\title{
Association of proinflammatory cytokines and islet resident leucocytes with islet dysfunction in type 2 diabetes
}

\author{
Matthew J. Butcher • Daniel Hallinger • Eden Garcia • \\ Yui Machida • Swarup Chakrabarti • Jerry Nadler • \\ Elena V. Galkina • Yumi Imai
}

Received: 16 July 2013 / Accepted: 1 November 2013 / Published online: 16 January 2014

(C) Springer-Verlag Berlin Heidelberg 2014

\begin{abstract}
Aims/hypothesis Chronic inflammation in type 2 diabetes is proposed to affect islets as well as insulin target organs. However, the nature of islet inflammation and its effects on islet function in type 2 diabetes remain unclear. Moreover, the immune cell profiles of human islets in healthy and type 2 diabetic conditions are undefined. We aimed to investigate the correlation between proinflammatory cytokine expression, islet leucocyte composition and insulin secretion in type 2 diabetic human islets.

Methods Human islets from organ donors with or without type 2 diabetes were studied. First and second phases of glucose-stimulated insulin secretion were determined by perifusion. The expression of inflammatory markers was obtained by quantitative PCR. Immune cells within human islets were analysed by FACS.

Results Type 2 diabetic islets, especially those without firstphase insulin secretion, displayed higher $C C L 2$ and $T N F a$ expression than healthy islets. CD45 ${ }^{+}$leucocytes were elevated in type 2 diabetic islets, to a greater extent in moderately functional type 2 diabetic islets compared with poorly
\end{abstract}

Elena V. Galkina and Yumi Imai contributed equally to this work.

Electronic supplementary material The online version of this article (doi:10.1007/s00125-013-3116-5) contains peer-reviewed but unedited supplementary material, which is available to authorised users.

M. J. Butcher · E. V. Galkina $(\bowtie)$

Department of Microbiology and Molecular Cell Biology, Eastern

Virginia Medical School, 700 West Olney Road, Norfolk,

VA 23507-1696, USA

e-mail: galkinev@evms.edu

D. Hallinger $\cdot$ E. Garcia $\cdot$ Y. Machida $\cdot$ S. Chakrabarti $\cdot$ J. Nadler $\cdot$

Y. Imai $(\square)$

Department of Internal Medicine, Strelitz Diabetes Center, Eastern

Virginia Medical School, 700 West Olney Road, Norfolk,

VA 23507-1696, USA

e-mail: imaiy@evms.edu functional ones, and corresponded with elevated $A L O X 12$ but not with $C C L 2$ or $T N F a$ expression. T and B lymphocytes and $\mathrm{CD} 11 \mathrm{c}^{+}$cells were detectable within both non-diabetic and type 2 diabetic islet leucocytes. Importantly, the proportion of B cells was significantly elevated within type 2 diabetic islets.

Conclusions/interpretation Elevated total islet leucocyte content and proinflammatory mediators correlated with islet dysfunction, suggesting that heterogeneous insulitis occurs during the development of islet dysfunction in type 2 diabetes. In addition, the altered $\mathrm{B}$ cell content highlights a potential role for the adaptive immune response in islet dysfunction.

Keywords 12 Lipoxygenase $\cdot$ B cell $\cdot$ CCL2 $\cdot$ Dendritic cells $\cdot$ Flow cytometry $\cdot$ Insulin secretion $\cdot$ Macrophages · Perifusion $\cdot$ T cell $\cdot$ TNF- $\alpha$

$\begin{array}{ll}\text { Abbreviations } \\ \text { 12LO } & \text { 12 Lipoxygenase } \\ \text { CCL } & \text { Chemokine (C-C motif) ligand } \\ \text { CXCL } & \text { Chemokine (C-X-C motif) ligand } \\ \text { DC } & \text { Dendritic cell } \\ \text { GSIS } & \text { Glucose-stimulated insulin secretion } \\ \text { IEQ } & \text { Islet equivalent } \\ \text { IIDP } & \text { Integrated Islet Distribution Program } \\ \text { SI } & \text { Stimulation index } \\ \text { SSC } & \text { Side scatter } \\ \text { Th } & \text { T helper }\end{array}$

\section{Introduction}

The pathogenesis of type 2 diabetes consists of insulin resistance and islet dysfunction [1]. Metabolic stress from excessive nutrition contributes to insulin resistance by provoking 
chronic inflammation in insulin target organs [1-3]. It is plausible that islet dysfunction is also related to global chronic inflammation in type 2 diabetes. Indeed, some clinical studies targeting IL-1 $\beta$ - and nuclear factor $\mathrm{kB}$-related inflammatory pathways improved aspects of type 2 diabetic beta cell function [4-6]. IL-1 $\beta$ and IL-12, as well as the chemokine (C-C motif) ligand 2 (CCL2) and CCL13, are increased in type 2 diabetic islets and circulation [2, 7, 8]. Similarly, some alterations in circulating leucocyte subsets have been reported in individuals with type 2 diabetes [3,9]. Peripheral blood $\mathrm{T}$ helper (Th)17 and Th1 cells are increased, but $\mathrm{T}$ regulatory cells are diminished in obese individuals with type 2 diabetes compared with obese controls $[10,11]$. Circulating $\mathrm{T}$ cells reactive to islets are detectable in type 2 diabetic patients [12]. Similarly, peripheral blood circulating B cells from individuals with type 2 diabetes secrete more IL- 8 but less IL-10, and support contact-dependent $\mathrm{T}$ cell activation [13]. However, it is unclear whether B or T cells are present and participate in inducing islet dysfunction. Thus, the mechanisms that connect adipose and islet tissue inflammation and dysfunction in type 2 diabetes are unclear [14].

In this respect, there is limited information concerning the impact of local inflammation on the deterioration of human islet function or the profile of islet-associated leucocytes during the development of type 2 diabetes. While most knowledge about the potential role of leucocytes in islet dysfunction is derived from mouse models of type 1 diabetes [15], several recent studies have aimed to examine the immune cell content of human type 2 diabetic islets. CD $68^{+}$leucocytes, which are mostly macrophages, were increased in histological studies of humans with type 2 diabetes $[16,17]$, suggesting that islet macrophages may play a role in type 2 diabetes. However, a comprehensive analysis is required to determine whether other leucocyte subsets exist within human islets, where they might orchestrate inflammation during type 2 diabetes.

Immune cell accumulation has been reported in multiple rodent models of type 2 diabetes, including $o b / o b$ mice, highfat-fed mice, Goto-Kakizaki rats and Zucker diabetic fatty rats, supporting the notion that inflammation may contribute to islet dysfunction $[16,18,19]$. Although animal models offer valuable insight into islet biology, human islets are known to differ from rodent islets in morphology [20, 21] and functionality [22], highlighting the importance of studying human islets. The scarcity and difficulty of procuring human islets has been a major hurdle in understanding the pathogenesis of islet failure during type 2 diabetes. In the present study, we applied a flow cytometry-based approach to examine the distribution of leucocyte subsets in nondiabetic and type 2 diabetic human islets, in combination with assessments of islet function and proinflammatory marker expression, to determine the relationship between inflammation and islet function.

\section{Methods}

Human islet culture Human islets were acquired from the Integrated Islet Distribution Program (IIDP; Duarte, CA, USA, for 40 donors, see electronic supplementary material [ESM] Methods) and Beta-Pro (Charlottesville, VA, USA, for three donors), with approval from the institutional review board at the Eastern Virginia Medical School. Islets were incubated overnight in CMRL-1066 containing 10\% FBS and $1 \%$ penicillin-streptomycin at $37^{\circ} \mathrm{C}$ and $5 \% \mathrm{CO}_{2}$ to recover from shipment. For cytokine treatments, a mixture of $0.57 \mathrm{mmol} / 1 \mathrm{TNF}-\alpha, 5.9 \mathrm{mmol} / \mathrm{l} \mathrm{IFN}-\gamma$ and $0.29 \mathrm{mmol} / 1$ IL-1 $\beta$ (all from BD Bioscience, San Jose, CA, USA) were added to the culture overnight.

Ex vivo perifusion assay A total of 500 islet equivalents (IEQ) of human islets were perifused at 3 or $23 \mathrm{mmol} / \mathrm{l}$ glucose (between 45 and $65 \mathrm{~min}$ ) [23]. The samples were collected at $1 \mathrm{ml} / \mathrm{min}$ for human insulin measurement by ELISA (Mercodia, Winston Salem, NC, USA). The islet insulin content was measured by ELISA after extraction by acidified ethanol [24]. Variables used to compare glucose-stimulated insulin secretion (GSIS) are detailed in ESM Methods.

Gene expression analyses cDNA was prepared from 500 IEQ of human islets, as described in ESM Methods. Gene expression was analysed using the TaqMan gene-expression assay (Invitrogen, Carlsbad, CA, USA), normalised against $\beta$ actin expression.

Flow cytometry A total of 5,000-7,000 IEQ islets digested with $0.025 \%$ trypsin and dispersed into single-cell suspensions were used for flow cytometry experiments (detailed in ESM Methods).

Statistics The data are presented as mean \pm SEM. Differences in numeric values between two groups were assessed using an unpaired Student's $t$ test or Mann-Whitney test. Categorical variables (Table 1) were compared with Fisher's exact test. Spearman's rank correlation coefficiency was obtained using GraphPad Prism version 5.00 (GraphPad Software, La Jolla, CA, USA). $p<0.05$ was considered significant.

\section{Results}

Impairment of GSIS in human type 2 diabetic islets GSIS was measured during perifusion to assess the functionalities of human islets (Fig. 1a). The characteristics of the islets from both cohorts were comparable, aside from a higher BMI in the type 2 diabetic cohort (Table 1). GSIS corrected for total insulin content varied widely in both cohorts (ESM Fig. 1a). 
Table 1 Characteristics of human islets

\begin{tabular}{llll}
\hline & Non-diabetes $(n=21)^{\mathrm{a}}$ & Type 2 diabetes $(n=18)^{\mathrm{a}}$ & Cytokine treatment (Fig. 4g, $n=4)$ \\
\hline Age, years & $44.8 \pm 2.9(47)$ & $51.2 \pm 1.7(54)$ & $31.3 \pm 4.2(33.5)$ \\
BMI, kg/m & $28.5 \pm 1.2(29.1)$ & $34.5 \pm 1.9^{*}(33.3)$ & $24.0 \pm 3.7(22.8)$ \\
Sex, male/female & $14 / 7(66.7 / 33.3)$ & $10 / 8(55.6 / 44.4)$ & $2 / 2(50 / 50)$ \\
Race W/B/H/A & $15 / 3 / 3 / 0(71.4 / 14.2 / 14.2 / 0)$ & $10 / 3 / 4 / 1(55.6 / 16.7 / 22.2 / 5.6)$ & $2 / 2 / 0 / 0(50 / 50 / 0 / 0)$ \\
Cause of death & & & 0 \\
$\quad$ CVA & $8(38.1)$ & $12(66.7)$ & $3(75)$ \\
$\quad$ Head trauma & $10(47.6)$ & $3(16.7)$ & 0 \\
$\quad$ Anoxia & $3(14.3)$ & $2(11.1)$ & $1(25)$ \\
$\quad$ Other & 0 & $1^{\mathrm{b}}(5.5)$ & $86.3 \pm 3.2(85)$ \\
\% Purity & $85.1 \pm 1.6(90)$ & $86.3 \pm 1.4(90)$ & $3 \pm 0(3)$ \\
Time in culture, days & $3.3 \pm 0.3(3)$ & $3.4 \pm 0.3(3)$ & $0 / 2 / 0 / 0 / 1 / 1$ \\
Isolation centre & & & $0 / 1 / 2 / 8 / 4 / 3$ \\
A/B/C/D/E/others ${ }^{\mathrm{c}} n$ & $2 / 4 / 3 / 4 / 6 / 2$ & &
\end{tabular}

Data are means \pm SEM (median) or $n(\%)$, unless otherwise stated

${ }^{\text {a }}$ Quantitative PCR, perifusion and flow cytometry analyses were performed using a selection of donor islets due to the limited quantity of islets. The sample size for each assay is shown in the figures

${ }^{\mathrm{b}}$ Excluded from flow cytometry

${ }^{\mathrm{c}}$ The list of isolation centres is available at http://iidp.coh.org/center_info.aspx

${ }^{*} p<0.01$ compared with the non-diabetic cohort

A, Asian; B, black; CVA, cerebrovascular accident; H, Hispanic; W, white

Therefore, we focused on the sizes of the first- and secondphase responses in a GSIS profile from each donor, as these variables are not affected by variations in total insulin content and are important indices of islet function (Fig. 1a, ESM Methods). The impairment in first-phase response is the earliest functional impairment of beta cells in type 2 diabetes [25, 26]. A prominent first phase followed by a sustained second phase was typically seen in perifused non-diabetic islets (Fig. 1a, A-E). In contrast, type 2 diabetic islets displayed a spectrum of GSIS impairment (Fig. 1a, F-Q), some with a weaker first-phase response (Fig. 1a, F-K) and others without a clear first-phase response but a retained second-phase response (Fig. 1a, L-O). In addition, some type 2 diabetic islets lacked GSIS (Fig. 1a, P and Q). Although the quality of islets could be affected by the isolation process, the range of GSIS impairment is reminiscent of progressive beta cell failure in type 2 diabetes [25, 26]. Based on Fig. 1a, the GSIS profile was expressed using two variables (Fig. 1b-e): the first/ second ratio, denoting the average first-phase over secondphase insulin secretion; and $\mathrm{AUC}_{44-67}$, denoting insulin secretion during the entire high-glucose perifusion period (ESM Methods). Both variables were significantly reduced in type 2 diabetic islets compared with non-diabetic islets (Fig. 1b, c). The stimulation index (SI), a widely used GSIS metric in batch assays, was calculated for comparisons (Fig. 1f, g). Although the SI correlated with the first/second ratio and $\mathrm{AUC}_{44-67}$ (ESM Fig. 1d, e), it showed substantial overlaps between non-diabetic and type 2 diabetic groups (Fig. 1f, g). The magnitude of the first-phase response (Fig. 1a) was better represented by the first/second ratio (Fig. 1d) than by SI during the entire high-glucose perifusion period (Fig. 1g) or SI calculated for the first phase only (Fig. 1h). For those without a clear first-phase response (samples L-Q), $\mathrm{AUC}_{44-67}$ and SI represented GSIS similarly well (Fig. 1e, g). Collectively, the perifusion of human islets permitted the characterisation of GSIS within the islet cohorts by providing the first/second ratio as a valuable variable.

The correlation between GSIS and proinflammatory gene expression in type 2 diabetic islets The association of inflammation with islet pathology was addressed by comparing GSIS with the expression of proinflammatory genes. TNFa and CCL2 expression levels were elevated overall in type 2 diabetic islets (Fig. 2a, b). 12 Lipoxygenase (12LO) reacts with arachidonic acid and is associated with inflammation in adipose tissues and islet dysfunction [27]. The expression of ALOX12 (the human gene encoding 12LO) was markedly increased only in some type 2 diabetic islets (Fig. 2c). The expression levels of $C C L 2$ and $T N F a$ were significantly elevated in type 2 diabetic islets with markedly reduced firstphase insulin secretion ( $<1.45$, 'Lo'), but unchanged in mildly impaired type 2 diabetic islets ( $>1.45$, 'Hi', Fig. 2d, e). Interestingly, elevated $A L O X 12$ expression was seen in mildly impaired type 2 diabetic islets (Fig. 2f). The relationship 
$\mathbf{a}$
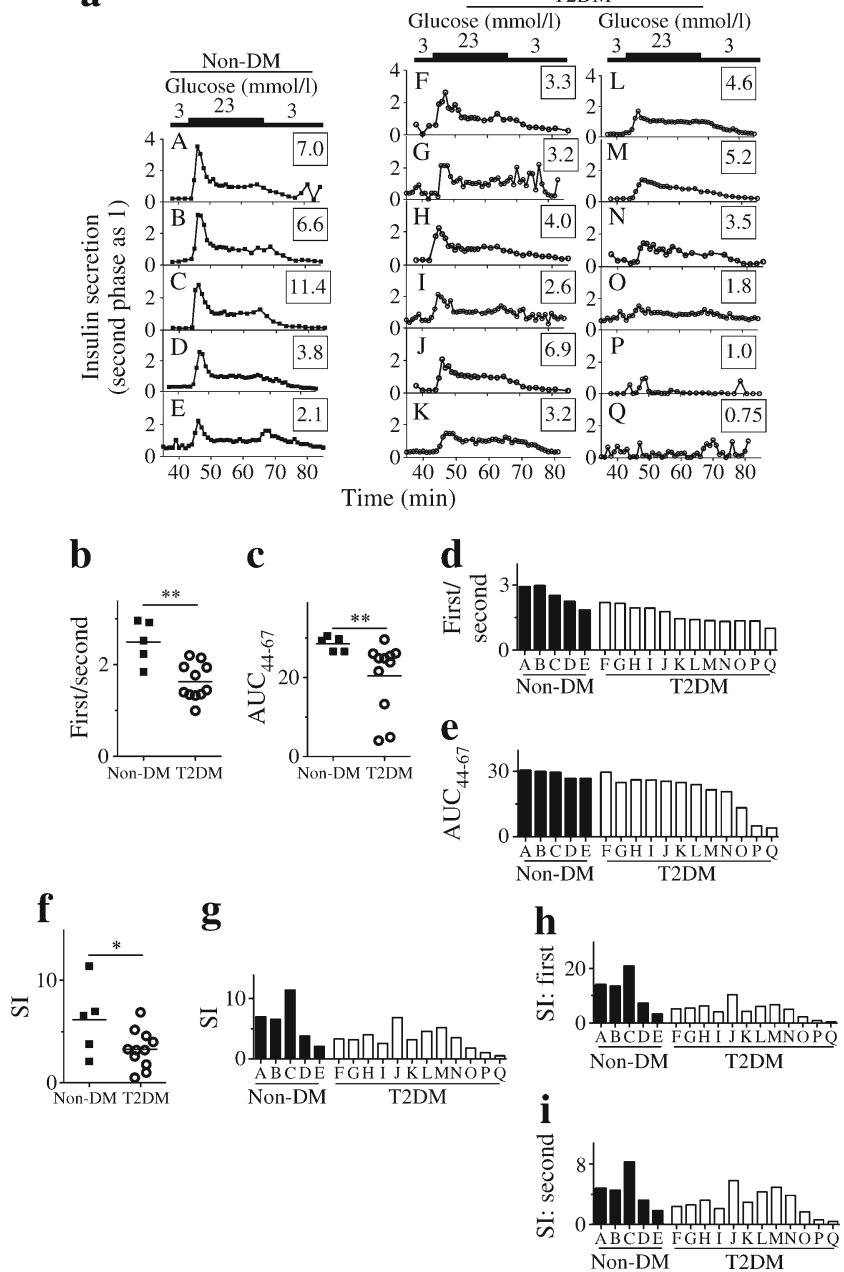

Fig. 1 Impairment in GSIS of human islets from type 2 diabetic donors. (a) Ex vivo perifusion of human islets from non-diabetic (non-DM, A-E) and type 2 diabetic (T2DM, F-Q) donors in response to the indicated concentration of glucose given for time periods shown on the horizontal line above. A total of $23 \mathrm{mmol} / \mathrm{l}$ glucose was given between 45 and $65 \mathrm{~min}$. Each graph indicates an individual donor. Numbers in rectangles indicate the SI (the ratio of average insulin secretion during $23 \mathrm{mmol} / \mathrm{l}$ glucose over $3 \mathrm{mmol} / \mathrm{l}$ glucose). (b-e) Two variables of GSIS determined based on (a) were compared between human islets from non-diabetic (non-DM; black squares, A-E) and type 2 diabetic (T2DM; open circles, F-Q) donors. The ratio of the first peak and second-phase response (b) and the AUC between time 44 and 67 min $\left(\mathrm{AUC}_{44-67}\right)$ (c), as determined in ESM Methods, are shown with the means indicated by horizontal lines, along with the data for individual donors in (d) and (e). The SI from the non-diabetic and type 2 diabetic groups (f) and each individual donor (g) is shown, with the means indicated by horizontal lines in (f). The SI during the first-phase response (time 46-48 $\mathrm{min}$ ) (h) and the secondphase response (time 55-60 min) (i) from an individual donor. ${ }^{*} p<0.05$; $* * p<0.01$

between GSIS and $A L O X 12$ levels was distinct from that of $C C L 2$ and TNFa (Fig. 2g-i). Both CCL2 and TNFa expression showed a significant negative correlation with GSIS (Fig. 2g, h), with tight correlation between the two (ESM Fig. 2a). Thus, CCL2 and TNFa expression levels closely reflect severe impairment in islet function, but
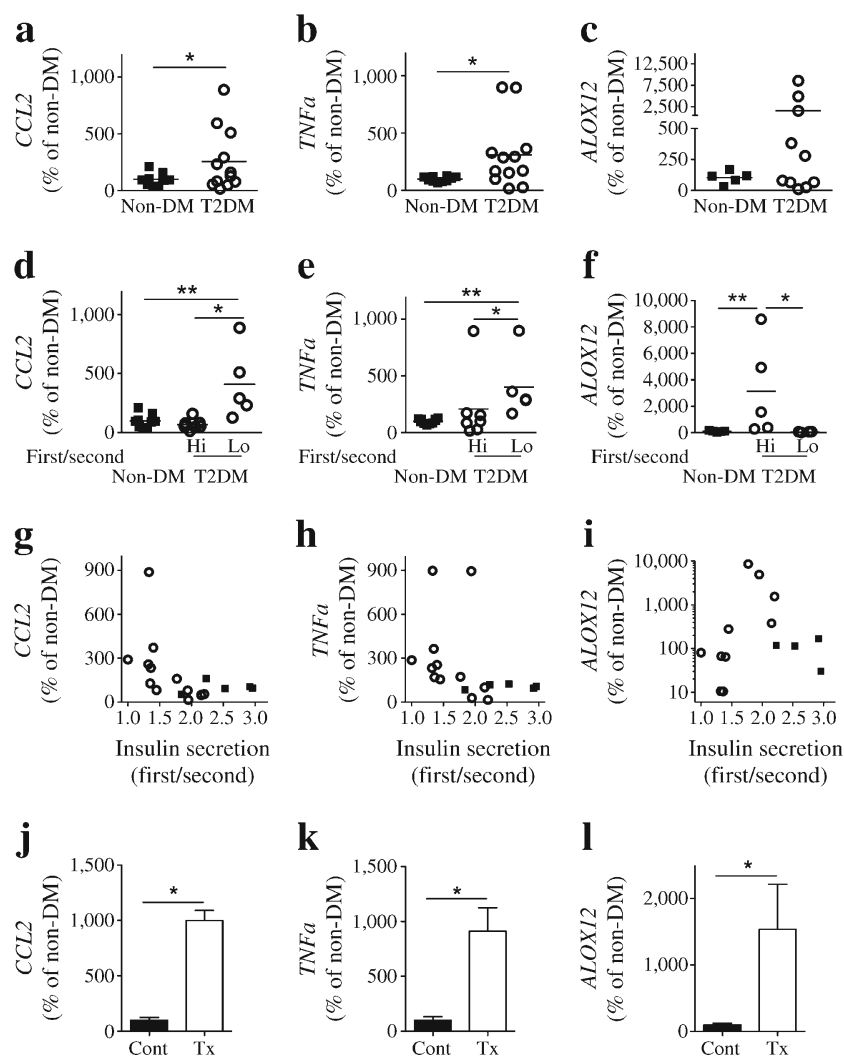

Fig. 2 The expression of proinflammatory genes was increased in human islets from type 2 diabetic donors. Quantitative PCR compared the expression levels of $C C L 2(\mathbf{a}, \mathbf{d}, \mathbf{g}), T N F a(\mathbf{b}, \mathbf{e}, \mathbf{h})$ and $A L O X 12$ $(\mathbf{c}, \mathbf{f}, \mathbf{i})$ between islets from non-diabetic (non-DM, black squares) and type 2 diabetic (T2DM, open circles) donors. Each symbol represents an individual donor with the means indicated as horizontal lines $(n=5-10$ for non-DM islets and $n=11-13$ for T2DM islets). The data were normalised to the expression of $\beta$ actin. (a-c) Comparisons were made between non-DM and T2DM islets. (d-f) Islets from T2DM donors were divided into high GSIS response $(\geq 1.45$, Hi) and low GSIS response $(<1.45$, Lo $)$ based on the ratio of first over second phase of insulin secretion (Fig. 1b). (g-i) The correlation between expression levels of proinflammatory genes and the ratio of first over second phase of insulin secretion (Fig. 1b) was examined. The expression of $C C L 2$ and $T N F a$ correlated with insulin secretion in $(\mathbf{g})(p<0.05)$ and $(\mathbf{h})(p<0.01)$, while no correlation was seen between ALOX12 expression and insulin secretion in (i). (j-l) Overnight treatment of non-diabetic islets with TNF- $\alpha$, IL- $1 \beta$ and IFN- $\gamma$ combined markedly increased the expression of CCL2 (j), TNFa (k) and ALOX12 (I). Cont, control; Tx, treatment. ${ }^{*} p<0.05 ;{ }^{*} p<0.01$

ALOX12 expression was uniquely increased in type 2 diabetic islets with moderate GSIS impairment. BMI did not correlate with any islet inflammatory marker or GSIS score (ESM Fig. 1f, 2b-d). In contrast to the discrepancy between $T N F a / C C L 2$ and $A L O X 12$ expression patterns in type 2 diabetic islets, all three genes were acutely upregulated when non-diabetic islets were treated with a mixture of TNF- $\alpha$, IL- $\beta$ and IFN- $\gamma$ (Fig. $2 j-1$ ), Thus, the mechanisms responsible for the increase of these genes in type 2 diabetic islets are different from those in acutely treated islets, a commonly used model to mimic type 1 diabetes-associated inflammation [28]. 
Increased number of leucocytes in human type 2 diabetic islets M1-like macrophage recruitment into islets has been reported in rodent models of type 2 diabetes and the number of $\mathrm{CD} 8^{+}$cells within islets has been found to be elevated in histological studies of pancreases from type 2 diabetic humans $[16,17]$. However, it is unknown if there are changes in the number or subsets of islet leucocytes in type 2 diabetes. Thus, we adapted a flow cytometry-based method to assess whether leucocyte subsets are present within human islets and if their numbers correlate with islet dysfunction. Flow cytometry offers an advantage over standard histological analyses by permitting the analysis of heterogeneous immune cell populations through the use of multiple surface antigen markers [29]. Non-lymphoid tissues contain a small number of resident leucocytes, which can expand during inflammation. Because of the low frequency and heterogeneous nature of tissue leucocytes, and the high degree of autofluorescence obtained from some non-lymphoid tissues, CD45, the common leucocyte antigen, is typically used to distinguish total leucocytes from tissue cells for subsequent analyses of leucocyte subsets [30-32]. Thus, we used CD45 as a marker to initially identify and examine the abundance of leucocytes within islet cell suspensions (Fig. 3a-f). To rule out possible contamination of the islet preparation with circulating leucocytes, we measured islet cell suspensions for $\mathrm{CD} 235 \mathrm{a}^{+}$erythrocytes, as previously described [31]. We estimate that $0.0007 \%$ of the islet leucocytes represent blood circulating leucocytes (data not shown). In addition, we performed simultaneous staining for endocrine cells and islet leucocytes, to confirm that CD45 cleanly distinguishes leucocytes from endocrine cells (ESM Fig. 3a). We also used Live/Dead Aqua dye to assess potential differences in the viability of islet leucocytes between non-diabetic and type 2 diabetic islets (ESM Fig. 4). The majority of $\mathrm{CD} 45^{+}$leucocytes $(>90 \%)$, as well as major leucocyte subsets, were viable within the islet microenvironment, and the percentage of viable CD45 $5^{+}$leucocytes was equivalent between the two cohorts (ESM Fig. 4). Finally, we detected no differences in analysed islet leucocyte antigen expression between mechanically and enzymatically dispersed islets, suggesting that the enzymatic digestion of human islets has no effect on the stability of the surface antigens used in these studies (ESM Fig. 5).

We next estimated the overall leucocyte cellularity within human islets based on CD45-positive leucocytes normalised to 1,000 IEQ. After correcting for cell loss during sample preparation, the abundance of $\mathrm{CD} 45^{+}$leucocytes per 1,000 IEQ obtained by flow cytometry was similar to that previously reported in histological estimates of islet leucocyte cellularity $[16,33]$. The number of $\mathrm{CD} 45^{+}$leucocytes was increased within type 2 diabetic islets (Fig. 3f). Since the degree of islet functionality varied widely within the type 2 diabetic islet cohort (Fig. 1), the number of islet leucocytes was compared between high and low insulin-secreting type 2 diabetic islets (Fig. 3g). In contrast to the negative relationship between

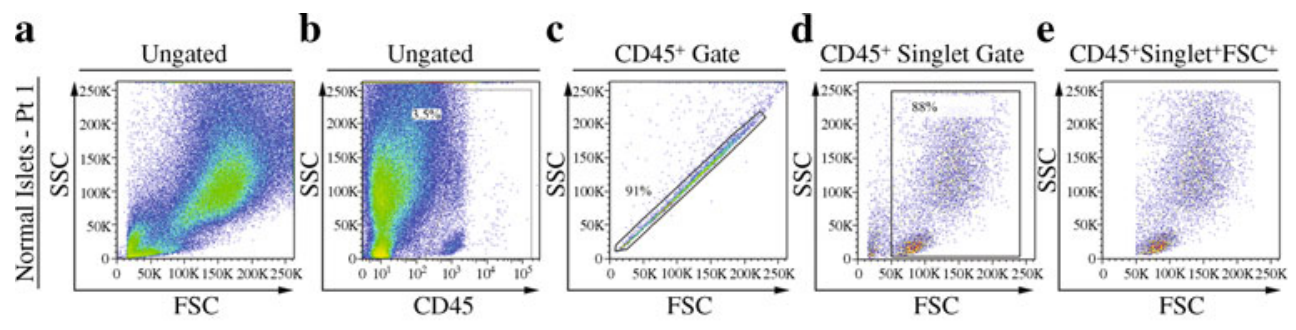

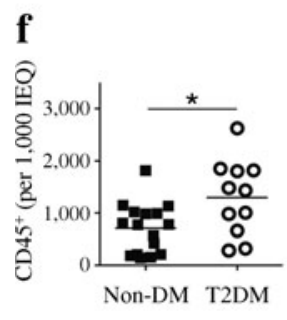

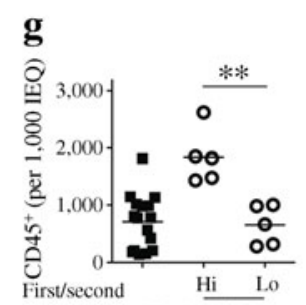

Non-DM $\overline{\mathrm{T} 2 \mathrm{DM}}$

Fig. 3 Human islet leucocytes could be detected by flow cytometry and were elevated in type 2 diabetic human islets. Examination of non-diabetic (non-DM, black squares) and type 2 diabetic islet (T2DM, open circles) CD45 ${ }^{+}$leucocyte content normalised to 1,000 IEQ. (a-e) Representative flow cytometry gating scheme for human islet leucocytes (patient 1 , nonDM, ESM Table 1). First, all of the acquired human islet data were gated on leucocytes using CD45 (b), the common leucocyte antigen. Next, cellular aggregates and events smaller than 50,000 FSC or larger than 250,000 SSC were excluded from the analyses, based on FSC-H/FSC-A (c) and $\mathrm{FSC} / \mathrm{SSC}$ variables (d). $\mathrm{K}$ indicates thousands, i.e. $50 \mathrm{~K}=50,000$ etc. (f) The number of normalised CD45 ${ }^{+}$leucocytes within the non-DM and
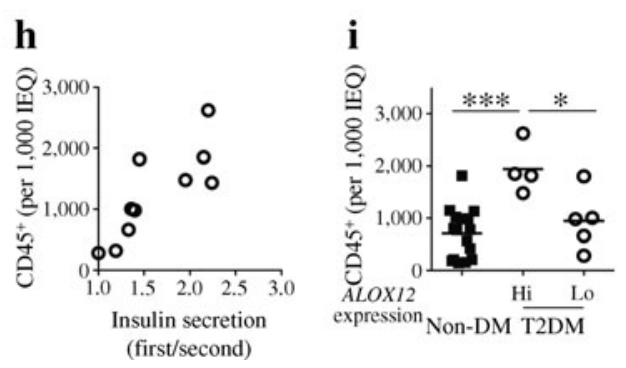

T2DM islet cohorts and (g) the number of normalised CD45 $5^{+}$leucocytes within non-DM, high GSIS T2DM islets (first/second $\geq 1.45$, Hi) and low GSIS T2DM islets (first/second $<1.45$, Lo). (h) Correlation between insulin secretion scores (GSIS) and the number of IEQ-normalised leucocytes. There was a positive correlation between the two $(p<0.01)$. Each symbol represents an individual donor, with the group means indicated as horizontal lines. (i) The number of $\mathrm{CD} 45^{+}$-normalised leucocytes within non-DM, T2DM with high $A L O X 12$ expression ( $\geq 168 \%$ of control, Hi) and low ALOX12 expression ( $<168 \%$ of control, Lo) by quantitative PCR. The percentage $168 \%$ was chosen based on the $95 \%$ CI of $A L O X 12$ expression in the non-DM cohort. ${ }^{*} p<0.05 ;{ }^{* *} p<0.01 ;{ }^{* *} p<0.005$ 
proinflammatory $C C L 2$ expression and insulin secretion, the number of $\mathrm{CD} 45^{+}$leucocytes was elevated within type 2 diabetic islets with preserved insulin secretion, in comparison with dysfunctional type 2 diabetic islets (Fig. 3g). A positive correlation was observed between GSIS (first/second-phase ratio) and the number of $\mathrm{CD}_{4} 5^{+}$leucocytes within type 2 diabetic islets (Fig. 3h); however, BMI and CCL2 and TNFa expression did not correlate with $\mathrm{CD} 45^{+}$leucocytes (ESM Fig. 3b-d). These data suggest that the accumulation of leucocytes within islets is associated with the pathology of type 2 diabetes, although the peak accumulation of leucocytes did not coincide with CCL2 expression. Altogether, other factors may affect the recruitment of immune cells, resulting in variable amounts of islet inflammation within both high- and lowinsulin-secreting type 2 diabetic islets. Interestingly, the increase in $\mathrm{CD}_{4} 5^{+}$leucocytes was strongly associated with elevated expression of $A L O X 12$ in type 2 diabetic islets ('Hi' vs 'Lo', Fig. 3i), suggesting that islet leucocytes may be an important source of $12 \mathrm{LO}$ production within type 2 diabetic islets. Alternatively, 12LO, which is also produced by beta cells [34], may support the recruitment of leucocytes to the islets.

Type 2 diabetic islets contain elevated levels of B cells Next, we further characterised the composition of $\mathrm{CD} 45^{+}$leucocytes within human islets. The donor populations are described in ESM Tables 1 and 2. Two major populations of CD45 leucocytes could be distinguished based on their forward scatter (FSC) and side scatter (SSC) profiles (Fig. 3e): a smaller (50,000-120,000 FSC; 0-50,000 SSC) and a larger population of leucocytes (100,000-200,000 FSC; 70,000 220,000 SSC), reminiscent of lymphocytes and myeloid cells, respectively. To date, limited information is available about the presence and functions of the immune cells in type 2 diabetic islets. Therefore, we examined the presence of the major leucocyte subsets, including $\mathrm{T}$ cells, B cells and myeloid cells, within islets. We assessed human islets for the presence of T lymphocytes using T cell marker CD3( $(\varepsilon)$ [35] and B lymphocytes with CD20 expression (Fig. 4) [36], based on fluorescence minus one and/or isotype control staining. Overall, T cells were the predominate lymphocytes within the human islets; however, the percentage of $\mathrm{CD}^{+} \mathrm{T}$ cells between type 2 diabetic and non-diabetic islets (Fig. 4a, e) was similar. Interestingly, while the percentage of $\mathrm{CD}^{+} \mathrm{T}$ cells distributed tightly within non-diabetic islets, the percentage varied widely within type 2 diabetic islets, with two patients (patients 21 and 22, ESM Table 2) having up to $60 \%$ and one patient (patient 31 ) with $1 \% \mathrm{CD}^{+} \mathrm{T}$ cells (Fig. $4 \mathrm{e}$ ).

An important role for B cells in the development of systemic and adipose inflammation has been reported in a mouse model of insulin resistance [37]. In parallel, a recent study with peripheral blood circulating B cells from type 2 diabetic individuals highlighted the unique phenotype and functions of these lymphocytes [38]. To test whether B cells are present within islets, we performed staining for $\mathrm{CD} 20$, a marker that is expressed by the majority of B cells, including pre-, resting and memory B cells. A small but distinguishable resident population of $\mathrm{CD} 20^{+} \mathrm{B}$ cells was present within nondiabetic and type 2 diabetic islets (Fig. 4c). Overall, the percentage of $\mathrm{B}$ cells was increased up to 2.2-fold in type 2 diabetic islets compared with non-diabetic controls (Fig. 4f). To assess whether human islet $\mathrm{T}$ cells may be activated in response to cytokines, we assessed TNF- $\alpha$-, IL- $1 \beta$ - and IFN- $\gamma$-treated non-diabetic islets for upregulation of the early $\mathrm{T}$ cell activation marker CD69 on intraislet memory T cells $\left(\mathrm{CD}^{+}{ }^{+} \mathrm{CD} 44^{+} \mathrm{CD} 45 \mathrm{RA}^{-} \mathrm{T}\right.$ cells). In this ex vivo system, memory $\mathrm{T}$ cells significantly upregulated CD69 in comparison to vehicle-treated controls (Fig. 4g). These results suggest that islet $\mathrm{T}$ cells are functional and can be activated in response to proinflammatory cytokines, likely through islet antigen presenting myeloid or B cells.

Next, we examined whether myeloid cells were altered between type 2 diabetic and non-diabetic islets (Fig. 5). As there are no completely unique markers for dendritic cells (DCs) or macrophages, we initially characterised islet myeloid cells based on CD11c and CD11b expression [39]. A noticeable population of $\mathrm{CD} 11 \mathrm{c}^{+}$cells was detected within islets from both non-diabetic (patient 18, Fig. 5a) and type 2 diabetic (patient 34, Fig. 5a) donors; however, the percentage of $\mathrm{CD} 11 \mathrm{c}^{+}$cells between non-diabetic and type 2 diabetic islets was similar (Fig. 5c). To further examine the phenotype of CD11 $\mathrm{c}^{+}$cells, we analysed the expression of CD11b by $\mathrm{CD} 11 \mathrm{c}^{+}$cells. The majority of $\mathrm{CD} 11 \mathrm{c}^{+}$myeloid cells also expressed CD11 $\mathrm{b}^{+}$(Fig. 5d-f), suggesting that these myeloid cells may represent $\mathrm{CD} 11 \mathrm{~b}^{+} \mathrm{CD} 11 \mathrm{c}^{+}$macrophages or DCs. The frequency of $\mathrm{CD} 11 \mathrm{~b}^{+} \mathrm{CD} 11 \mathrm{c}^{+}$cells was unchanged between non-diabetic and type 2 diabetic islets and varied greatly within both cohorts (Fig. 5f). To characterise the nature of islet $\mathrm{CD} 11 \mathrm{~b}^{+} \mathrm{CD} 11 \mathrm{c}^{+}$myeloid cells the expression of CD86, a $\mathrm{T}$ cell costimulatory molecule, was assessed (Fig. $5 \mathrm{~g}$, h). The majority of islet $\mathrm{CD} 11 \mathrm{~b}^{+} \mathrm{CD} 11 \mathrm{c}^{+}$cells from non-diabetic and type 2 diabetic individuals expressed CD86 (Fig. 5g, h). Together, our data demonstrate the presence of $\mathrm{T}$ and $\mathrm{B}$ lymphocytes, and myeloid cell subsets within non-diabetic human islets, that likely reflect constitutive homing of leucocytes and significant alterations in the immune content of type 2 diabetic islets. These data also highlight the potential utility of flow cytometry for analysing islet leucocytes and inflammation during the development of type 2 diabetes.

\section{Discussion}

In this study, we have established a strong correlation between the proinflammatory cytokine TNF- $\alpha$ and the chemokine CCL2 with GSIS in type 2 diabetic human islets. We found 
a

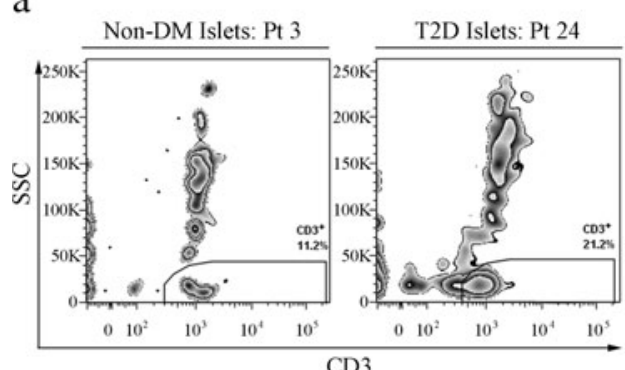

c

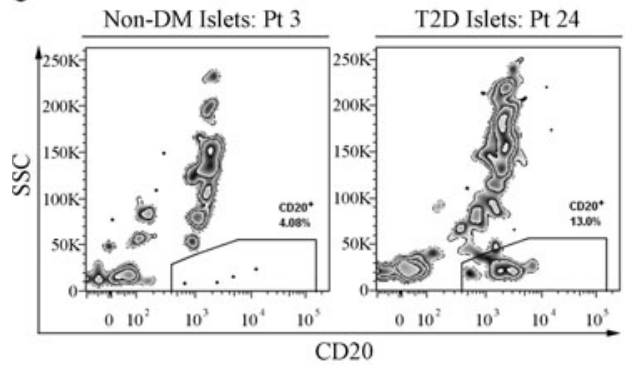

b

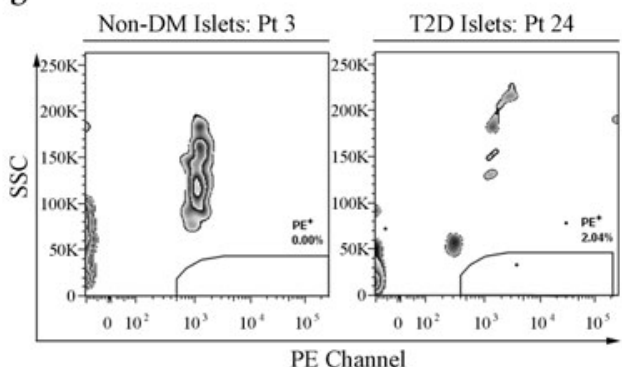

d

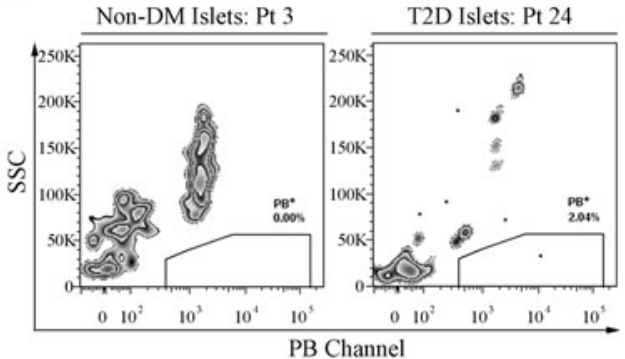

e

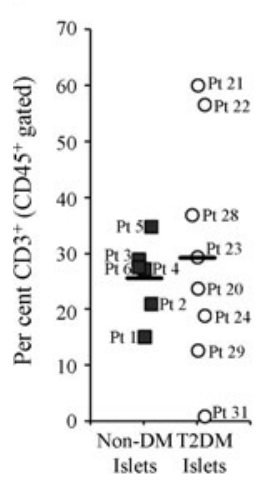

$\mathrm{f}$

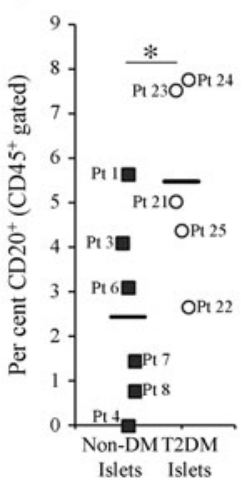

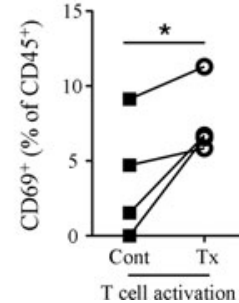

shown (d). $\mathrm{K}$ indicates thousands, i.e. $50 \mathrm{~K}=50,000$ etc. (e) The percentage of islet $\mathrm{CD}^{+} \mathrm{T}$ lymphocytes within $\mathrm{CD} 45^{+}$singlet ${ }^{+} \mathrm{FSC}^{+}$gated nonDM (black squares) and T2DM (open circles) islet donors. Each symbol represents an individual donor, with the group means indicated as horizontal lines. (f) The percentage of gated $\mathrm{CD} 20^{+} \mathrm{B}$ lymphocytes, as represented in (c). (g) The effects of overnight treatment of non-DM islets with of TNF- $\alpha$, IL- $1 \beta$ and IFN- $\gamma$ on the expression of the activation marker $\mathrm{CD} 69$ within $\mathrm{CD} 45^{+} \mathrm{CD} 3^{+} \mathrm{CD} 44^{+} \mathrm{CD} 45 \mathrm{RA}^{-}$memory T cells. The symbols depict non-treated (black squares) and treated (open circles) islets. ${ }^{*} p<0.05$

It is noteworthy that the perifusion of human islets from clinically labelled type 2 diabetic donors unanimously showed blunting or loss of first-phase insulin secretion, suggesting that islets from type 2 diabetic donors retain features of islet dysfunction ex vivo. In comparison with previous studies that used glucose-ramp or batch assays [40,41], we determined both the first- and second-phase GSIS responses in a large cohort of type 2 diabetic islets. The wide spectrum of impairment in firstand second-phase insulin secretion that we observed may reflect a gradual decline in functional beta cell mass, which is
Low first-phase insulin secretion upon i.v. glucose injection is a pathognomonic feature of human type 2 diabetes $[25,26]$. 


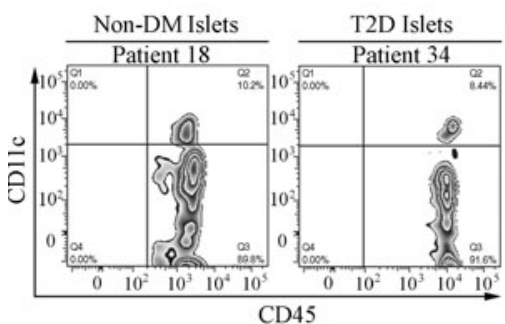

d

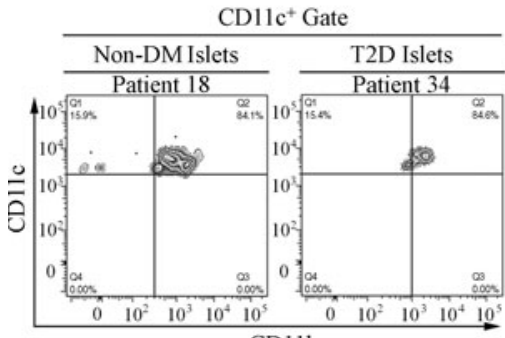

CDIlb b

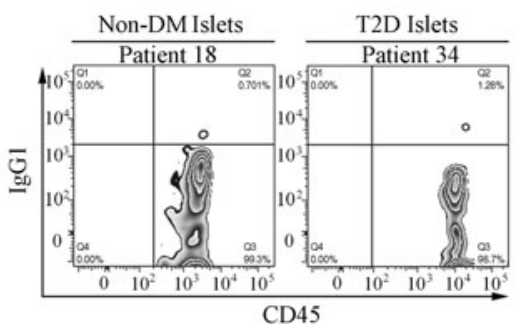

e

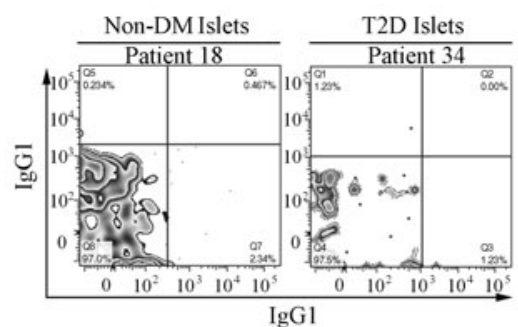

c

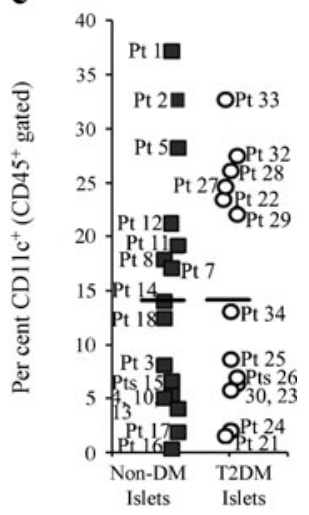

f

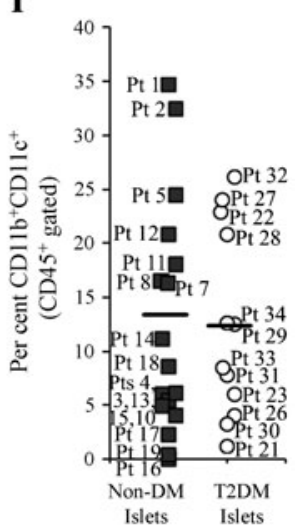

h

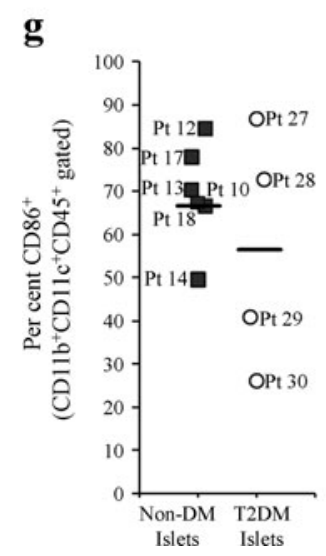

Fig. 5 Resident islet CD86-expressing CD11 ${ }^{+} \mathrm{CD} 11 \mathrm{c}^{+}$myeloid cells were present within non-diabetic and type 2 diabetic human islets. (a) Representative flow cytometry plots of $\mathrm{CD}_{4} 5^{+}$singlet ${ }^{+} \mathrm{FSC}^{+}$gated CD11 $\mathrm{c}^{+}$myeloid cells from non-diabetic (non-DM, patient 18) and type 2 diabetic (T2DM, patient 34) islet donors. The gates were set based on corresponding islet isotype control specimens (b). (c) Quantification of the percentage of $\mathrm{CD} 11 \mathrm{c}^{+}$myeloid cells within $\mathrm{CD} 45^{+}$singlet ${ }^{+} \mathrm{FSC}^{+}$ gated leucocytes. (d) Representative flow cytometry plots of

considered to be responsible for the progression of type 2 diabetes in humans [26]. The IIDP in the USA is an invaluable resource that facilitates access to a large number of islet donors. However, the medical history details available to researchers are currently limited (see ESM Methods). Future studies should determine whether the clinical history of a donor, including the duration and severity of type 2 diabetes, correlates with GSIS and islet leucocyte content ex vivo.

Several lines of evidence suggest that the levels of proinflammatory cytokines such as IL-1 $\beta$, IL-8 and IL-12 and chemokines CCL2, CCL13 and chemokine (C-X-C motif) ligand 10 (CXCL10) are elevated in type 2 diabetic islets 
$[7,8,14,42]$. However, it is unclear whether proinflammatory cytokines and chemokines are definitively associated with the development of islet dysfunction in type 2 diabetes. Our study provides compelling evidence for a negative correlation between the levels of CCL2 and TNF- $\alpha$ within type 2 diabetic islets and their functions, as determined by GSIS. CCL2 and $\mathrm{TNF}-\alpha$ levels were significantly elevated in dysfunctional type 2 diabetic islets in comparison with moderately functional type 2 diabetic islets, indicating the existence of several subgroups with different levels of inflammation within type 2 diabetic individuals. Surprisingly, $A L O X 12$, which is strongly associated with inflammation in adipose and other tissues [27], was upregulated within moderately functional but not dysfunctional type 2 diabetic islets, indicating that 12LO may play a role in islet dysfunction at early certain stages of the pathogenesis and that beta cell production of 12LO might participate in the early homing of leucocytes to islets. Alternatively, increased $A L O X 12$ expression may originate from non-beta cells, considering the correlation between ALOX12 expression and the abundance of $\mathrm{CD}^{+} 5^{+}$leucocytes.

M1-like macrophages are recruited into islets in rodent type 2 diabetes models and, similarly, $\mathrm{CD} 68^{+}$macrophages are elevated within human T2D islets $[16,17,43]$. To further determine if the immune system is associated with the pathology of type 2 diabetes, we examined the overall abundance of leucocytes and leucocyte subsets within human islets from non-diabetic and type 2 diabetic individuals. Importantly, we observed evidence of increased accumulation of CD $45^{+}$ leucocytes within type 2 diabetic islets, which strongly correlated with islet function. To our surprise, individuals with moderately functional islets possessed significantly more leucocytes than markedly dysfunctional type 2 diabetic islets. Based on these results, initial steps in the development of type 2 diabetes may be accompanied by an influx of CD $45^{+}$ leucocytes, which likely supports active islet inflammation. In contrast, at an advanced stage of type 2 diabetes, significant beta cell damage and apoptosis due to oxidative stress, endoplasmic reticulum stress and mitochondrial dysfunction may provide less support for the recruitment of leucocytes to type 2 diabetic islets. Together, these results suggest that the accumulation of leucocytes within islets is associated with the pathology of type 2 diabetes, but the recruitment of leucocytes may occur in a temporal, stage-dependent manner. Considering the variable degrees of islet inflammation within high- and lowinsulin-secreting type 2 diabetic islets, other factors such as the management of the individual's diabetes and end-of-life treatment may modify the recruitment of leucocytes.

Chronic low-grade inflammation resulting from changes in lymphocyte and myeloid cell subsets promotes and exacerbates insulin resistance, which, together with islet dysfunction, defines type 2 diabetes. We detected an increased accumulation of $\mathrm{B}$ cells within type 2 diabetic islets. Recent reports suggest that circulating $\mathrm{B}$ cells are hyperactivated in type 2 diabetic patients and elicit $\mathrm{T}$ cell-derived proinflammatory TNF- $\alpha$, IL-17A and IL-6 production in T cell/B cell cocultures [9]. Thus, an elevated proportion of islet $\mathrm{B}$ lymphocytes may work together with costimulatory molecule-expressing myeloid cells $\left(\mathrm{CD} 86^{+}\right.$cells) to affect islet $\mathrm{T}$ cell activation or serve as "accessory cells" to promote islet-specific $\mathrm{T}$ cell proliferation, as shown for islet $\mathrm{B}$ lymphocytes in the non-obese diabetic mouse model [44].

Interestingly, comparable levels of $\mathrm{CD}^{+} \mathrm{T}$ cells and $\mathrm{CD}_{11 \mathrm{c}^{+}}$myeloid cells were present in both non-diabetic and type 2 diabetic islets. Islets treated with TNF- $\alpha$, IL- $1 \beta$ and IFN- $\gamma$ demonstrated that islet memory T cells are responsive to cytokines and may become activated during inflammation. Importantly, subtle changes in the proportion of $\mathrm{T}$ and $\mathrm{B}$ cell subsets may exist in type 2 diabetic islets, in addition to changes in the overall abundance of $\mathrm{T}$ and $\mathrm{B}$ cells within the islet. Future studies are required to determine if the overall abundance and differentiation of $T$ cell subsets are affected by the elevated number of islet $\mathrm{B}$ cells.

Recent studies have demonstrated that several DC subsets are present within rodent pancreatic islets, where they may play proinflammatory or tolerogenic roles in the context of type 1 diabetes [32, 45]. Two subsets of islet DCs with distinct functions are found within healthy murine islets.

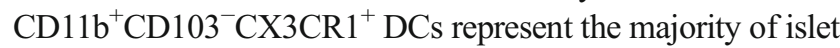
DCs with high phagocytic, but low antigen presentation activity [32]. In contrast, a small subset of $C D 11 b^{\text {low }}$ $\mathrm{CD}_{103}{ }^{+} \mathrm{CX} 3 \mathrm{CR} 1^{-} \mathrm{DCs}$ is able to migrate to the draining lymph node and cross-present antigens. In addition, suppressive $\mathrm{CD} 11 \mathrm{~b}^{+} \mathrm{CD} 11 \mathrm{c}^{+}$tolerogenic DCs have been described in a non-obese diabetic mouse model [45]. Multiple myeloid cell subsets may be similarly present within human islets, where they may participate in $\mathrm{T}$ cell activation and the development of islet dysfunction in type 2 diabetes. Indeed, sizeable populations of $\mathrm{CD} 11 \mathrm{c}^{+}$cells are present in non-diabetic and type 2 diabetic human islets, and further characterisation of $\mathrm{CD} 11 \mathrm{c}^{+}$ cells will be required to determine their roles in type 2 diabetes.

Collectively, our results demonstrate that insulitis is associated with and may participate in the deterioration of islet function in human type 2 diabetes. CCL2 and TNFa expression were strongly correlated with severe GSIS impairment, while the abundance of $A L O X 12$ and $\mathrm{CD} 45^{+}$leucocytes correlated with moderate impairment in GSIS, providing evidence for a complex interplay between islets and the immune system. Moreover, the current study highlights the potential importance of B lymphocytes in human islet biology. The detection of leucocyte populations in non-diabetic and type 2 diabetic human islets may not only provide insight into the physiologic role of immune cells associated with islets, but also highlight new directions for studying inflammation in type 2 diabetes. This could lead to new, more targeted therapies to prevent the decline of functional beta cell mass in patients with type 2 diabetes. 
Acknowledgements Human islets were provided to J. Nadler and Y. Imai by the IIDP. We thank J. Kaddis and B. Olack of the IIDP for assisting with documentation on the IIDP and donor data.

Funding This work was supported by the Juvenile Diabetes Research Foundation $(\mathrm{JN})$, grants from the National Institutes of Health to JN (R01-HL112605) and YI (R01-DK090490), and by the IIDP pilot programme (YI), a BD Pharmingen Research Grant (EVG), AstraZeneca $(\mathrm{JN})$ and start-up funds from the Eastern Virginia Medical School (EVG)

Duality of interest The authors declare that there is no duality of interest associated with this manuscript.

Contribution statement JN, EVG and YI contributed to the study conception and design. MJB, EVG (flow cytometry), DH, EG, YM (GSIS, quantitative PCR), SC (quantitative PCR) and YI (GSIS, quantitative PCR, flow cytometry) were responsible for the acquisition and analysis of the data. MJB, EVG and YI interpreted the data, drafted the manuscript and critically revised the manuscript for important intellectual content. DH, EG, YM, SC and JN also revised the manuscript. All authors approved the final version of the manuscript.

\section{References}

1. Nolan CJ, Damm P, Prentki M (2011) Type 2 diabetes across generations: from pathophysiology to prevention and management. Lancet 378:169-181

2. Donath MY, Shoelson SE (2011) Type 2 diabetes as an inflammatory disease. Nat Rev Immunol 11:98-107

3. Lumeng CN, Saltiel AR (2011) Inflammatory links between obesity and metabolic disease. J Clin Investig 121:2111-2117

4. Cavelti-Weder C, Babians-Brunner A, Keller C et al (2012) Effects of gevokizumab on glycemia and inflammatory markers in type 2 diabetes. Diabetes Care 35:1654-1662

5. Donath MY, Dalmas E, Sauter NS, Boni-Schnetzler M (2013) Inflammation in obesity and diabetes: islet dysfunction and therapeutic opportunity. Cell Metab 17:860-872

6. Goldfine AB, Fonseca V, Jablonski KA, Pyle L, Staten MA, Shoelson SE (2010) The effects of salsalate on glycemic control in patients with type 2 diabetes: a randomized trial. Ann Intern Med 152:346-357

7. Igoillo-Esteve M, Marselli L, Cunha DA et al (2010) Palmitate induces a pro-inflammatory response in human pancreatic islets that mimics CCL2 expression by beta cells in type 2 diabetes. Diabetologia 53:1395-1405

8. Taylor-Fishwick DA, Weaver JR, Grzesik W et al (2013) Production and function of IL-12 in islets and beta cells. Diabetologia 56:126-135

9. Nikolajczyk BS, Jagannathan-Bogdan M, Denis GV (2012) The outliers become a stampede as immunometabolism reaches a tipping point. Immunol Rev 249:253-275

10. Jagannathan-Bogdan M, McDonnell ME, Shin H et al (2011) Elevated proinflammatory cytokine production by a skewed $\mathrm{T}$ cell compartment requires monocytes and promotes inflammation in type 2 diabetes. J Immunol 186:1162-1172

11. Zeng C, Shi X, Zhang B et al (2012) The imbalance of Th17/Th1/ Tregs in patients with type 2 diabetes: relationship with metabolic factors and complications. J Mol Med (Berl) 90:175-186

12. Brooks-Worrell BM, Reichow JL, Goel A, Ismail H, Palmer JP (2011) Identification of autoantibody-negative autoimmune type 2 diabetic patients. Diabetes Care 34:168-173

13. Jagannathan M, McDonnell M, Liang Y et al (2010) Toll-like receptors regulate $\mathrm{B}$ cell cytokine production in patients with diabetes. Diabetologia 53:1461-1471
14. Imai Y, Dobrian AD, Morris MA, Nadler JL (2013) Islet inflammation: a unifying target for diabetes treatment? Trends Endocrinol Metab 24:351-360

15. Lehuen A, Diana J, Zaccone P, Cooke A (2010) Immune cell crosstalk in type 1 diabetes. Nat Rev Immunol 10:501-513

16. Ehses JA, Perren A, Eppler E et al (2007) Increased number of islet-associated macrophages in type 2 diabetes. Diabetes 56: 2356-2370

17. Richardson SJ, Willcox A, Bone AJ, Foulis AK, Morgan NG (2009) Islet-associated macrophages in type 2 diabetes. Diabetologia 52:1686-1688

18. Homo-Delarche F, Calderari S, Irminger JC et al (2006) Islet inflammation and fibrosis in a spontaneous model of type 2 diabetes, the GK rat. Diabetes 55:1625-1633

19. Jones HB, Nugent D, Jenkins R (2010) Variation in characteristics of islets of Langerhans in insulin-resistant, diabetic and non-diabetic-rat strains. Int J Exp Pathol 91:288-301

20. Cabrera O, Berman DM, Kenyon NS, Ricordi C, Berggren PO, Caicedo A (2006) The unique cytoarchitecture of human pancreatic islets has implications for islet cell function. Proc Natl Acad Sci U S A 103:2334-2339

21. Brissova M, Fowler MJ, Nicholson WE et al (2005) Assessment of human pancreatic islet architecture and composition by laser scanning confocal microscopy. J Histochem Cytochem Off J Histochem Soc 53:1087-1097

22. MacDonald MJ, Longacre MJ, Stoker SW et al (2011) Differences between human and rodent pancreatic islets: low pyruvate carboxylase, atp citrate lyase, and pyruvate carboxylation and high glucosestimulated acetoacetate in human pancreatic islets. J Biol Chem 286:18383-18396

23. Imai Y, Patel HR, Doliba NM, Matschinsky FM, Tobias JW, Ahima RS (2008) Analysis of gene expression in pancreatic islets from diet-induced obese mice. Physiol Genomics 36:43-51

24. Imai Y, Patel HR, Hawkins EJ, Doliba NM, Matschinsky FM, Ahima RS (2007) Insulin secretion is increased in pancreatic islets of neuropeptide Y-deficient mice. Endocrinology 148:57165723

25. Brunzell JD, Robertson RP, Lerner RL et al (1976) Relationships between fasting plasma glucose levels and insulin secretion during intravenous glucose tolerance tests. J Clin Endocrinol Metab 42:222-229

26. Kahn SE, Zraika S, Utzschneider KM, Hull RL (2009) The beta cell lesion in type 2 diabetes: there has to be a primary functional abnormality. Diabetologia 52:1003-1012

27. Dobrian AD, Lieb DC, Cole BK, Taylor-Fishwick DA, Chakrabarti SK, Nadler JL (2011) Functional and pathological roles of the 12- and 15-lipoxygenases. Prog Lipid Res 50:115-131

28. Delaney CA, Pavlovic D, Hoorens A, Pipeleers DG, Eizirik DL (1997) Cytokines induce deoxyribonucleic acid strand breaks and apoptosis in human pancreatic islet cells. Endocrinology 138:2610 2614

29. Beare A, Stockinger H, Zola H, Nicholson I (2008) Monoclonal antibodies to human cell surface antigens. Curr Protoc Immunol Appendix $4: 4 \mathrm{~A}$

30. Butcher MJ, Gjurich BN, Phillips T, Galkina EV (2012) The IL-17A/ IL-17RA axis plays a proatherogenic role via the regulation of aortic myeloid cell recruitment. Circ Res 110:675-687

31. Galkina E, Kadl A, Sanders J, Varughese D, Sarembock IJ, Ley K (2006) Lymphocyte recruitment into the aortic wall before and during development of atherosclerosis is partially L-selectin dependent. J Exp Med 203:1273-1282

32. Yin N, Xu J, Ginhoux F et al (2012) Functional specialization of islet dendritic cell subsets. J Immunol 188:4921-4930

33. Pisania A, Weir GC, O'Neil JJ et al (2010) Quantitative analysis of cell composition and purity of human pancreatic islet preparations. Lab Investig J Techn Methods Pathol 90:1661-1675 
34. Weaver JR, Holman TR, Imai Y et al (2012) Integration of pro-inflammatory cytokines, 12-lipoxygenase and NOX-1 in pancreatic islet beta cell dysfunction. Mol Cell Endocrinol 358:88-95

35. Gold DP, Puck JM, Pettey CL et al (1986) Isolation of cDNA clones encoding the $20 \mathrm{~K}$ non-glycosylated polypeptide chain of the human $\mathrm{T}$ cell receptor/T3 complex. Nature 321:431-434

36. Tedder TF, Streuli M, Schlossman SF, Saito H (1988) Isolation and structure of a cDNA encoding the B1 (CD20) cell-surface antigen of human B lymphocytes. Proc Natl Acad Sci U S A 85: 208-212

37. Winer DA, Winer S, Shen L et al (2011) B cells promote insulin resistance through modulation of T cells and production of pathogenic IgG antibodies. Nat Med 17:610-617

38. DeFuria J, Belkina AC, Jagannathan-Bogdan M et al (2013) B cells promote inflammation in obesity and type 2 diabetes through regulation of $\mathrm{T}$ cell function and an inflammatory cytokine profile. Proc Natl Acad Sci U S A 110:5133-5138

39. Geissmann F, Gordon S, Hume DA, Mowat AM, Randolph GJ (2010) Unravelling mononuclear phagocyte heterogeneity. Nat Rev Immunol $10: 453-460$
40. Del Guerra S, Lupi R, Marselli L et al (2005) Functional and molecular defects of pancreatic islets in human type 2 diabetes. Diabetes 54:727-735

41. Deng S, Vatamaniuk M, Huang X et al (2004) Structural and functional abnormalities in the islets isolated from type 2 diabetic subjects. Diabetes 53:624-632

42. Boni-Schnetzler M, Thorne J, Parnaud G et al (2008) Increased interleukin (IL)-1beta messenger ribonucleic acid expression in beta-cells of individuals with type 2 diabetes and regulation of IL-1beta in human islets by glucose and autostimulation. J Clin Endocrinol Metab 93:4065-4074

43. Eguchi K, Manabe I, Oishi-Tanaka Y et al (2012) Saturated fatty acid and TLR signaling link beta cell dysfunction and islet inflammation. Cell Metab 15:518-533

44. Carrillo J, Puertas MC, Alba A et al (2005) Islet-infiltrating B cells in nonobese diabetic mice predominantly target nervous system elements. Diabetes 54:69-77

45. Kriegel MA, Rathinam C, Flavell RA (2012) Pancreatic islet expression of chemokine CCL2 suppresses autoimmune diabetes via tolerogenic

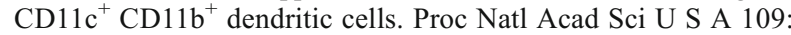
$3457-3462$ 